\title{
Effect of Dune Sand on the Properties of Flowing Sand-Concrete (FSC)
}

\author{
Tayeb Bouziani, ${ }^{1), 2), *}$ Madani Bederina, ${ }^{2), 3)}$ and Mourad Hadjoudja ${ }^{3)}$
}

\author{
(Received January 3, 2012, Revised February 13, 2012, Accepted February 21, 2012)
}

\begin{abstract}
Sand-concrete is being researched for potential usage in construction in Saharan regions of Algeria, because of shortage in coarse aggregate resources. This research work deals with the effect of dune sand, available in huge quantities in these regions, on the properties of flowing sand-concrete (FSC) prepared with different proportions of dune and river sands. Mini-cone slump test, v-funnel flow-time test and viscosity measurements were used to characterize the behaviour of FSC in fresh state. The 28day compressive strength was also determined. Test results show that an optimal content of dune sand, which makes satisfied fresh and hardened properties of FSC, is obtained. Moreover, the obtained flow index (constant b) calculated by the help of power-law viscosity model is successfully correlated to the experimental results of v-funnel flow time.
\end{abstract}

Keywords: flowing sand concrete, dune sand, fresh properties, viscosity, compressive strength.

\section{Introduction}

Due to the scarcity of aggregates in the south of Algeria and the high cost of their transportation from other regions, there has been a growing interest in the use of sand-concrete. Several research works have investigated the use of sand as a substitute for coarse aggregate to make sand-concrete, which has mechanical strength comparable to conventional concretes. ${ }^{1-4}$ Usually, sand-concrete consists of a mixture of sands, cement, one or more admixtures, additions and water. It is to be distinguished from a conventional concrete by its high proportion of sand. It is also distinguished from mortar by its cement content (low dosage of cement) and especially by its destination, (sand-concrete is primarily intended for more traditional uses). This advantage becomes extremely interesting when sand-concrete can reach certain fluidity in order to improve some of their performances. In France, Sablocrete project has allowed establishing a standard and proposing a mix design method for sand-concrete. This project has also reported many applications of flowing sand-concrete (FSC) in concrete repairs, soil grouting and deep foundations for building. ${ }^{1}$

At present, local sands, which are only slightly or not at all

\footnotetext{
1)Laboratory of Civil Engineering Research (LRGC), University Ammar Telidji of Laghouat, BP37G route de Ghardaia, Laghouat 03000, Algeria. *Corresponding Author; E-mail: t.bouziani@yahoo.fr ${ }^{2)}$ Structures Rehabilitation and Materials Laboratory (SREML), University Ammar Telidji of Laghouat, BP37G route de Ghardaia, Laghouat 03000, Algeria

3)Laboratory of Civil Engineering Research (LRGC), University Ammar Telidji of Laghouat, BP37G route de Ghardaia, Laghouat 03000, Algeria.

Copyright (c) 2012, Korea Concrete Institute. All rights reserved, including the making of copies without the written permission of the copyright proprietors.
}

extracted, constitute sizable deposits, and their application as construction materials would respond to the ecological and economic considerations raised by current trends. ${ }^{2}$ Dune sand (DS), in particular, is available in huge quantities in the Sahara and cover more than $60 \%$ of the area of Algeria.

In concrete design, the dosage and fineness of aggregates have an important influence on quality of fresh and hardened properties. Brouwers and Radix ${ }^{5}$ have found that the fine sand is a useful component in optimizing the particle size distribution and thereby increasing flowability, stability and mechanical properties of the concrete mixes. Bédérina et $\mathrm{al}^{2}$, show in a study on the reuse of local sands (dune and river sands) in sand -concrete, the importance of limestone filler content on the correction of particle size distribution and improvement of rheological and mechanical properties of studied sand-concretes.

Due to the finesses of aggregates in sand-concrete, it requires a high water demand and a large amount of cement than other types of concretes in order to achieve high fluidity. The increase in water content leads to detrimental effects including bleeding and segregation as well as weak interfaces between granular materials. ${ }^{6,7}$ Moreover, high cement content may cause severe creep and drying shrinkage, ${ }^{8}$ and may lead to classify sand-concrete as a mortar. For these reasons, sand-concrete mixes always contain a superplasticizer and a large quantity of additions. The superplasticizer is necessary for producing a flowable mix, while the addition of fine materials are required to maintain sufficient viscosity, hence reducing bleeding, segregation and settlement. However, excessive addition of fine particles can results in a considerable increase in the specific surface area of the powder, which results in an increase of water demand to achieve a given consistency.

In this work, a study on the effect of DS content on fresh properties and compressive strength of FSC is presented. For this, four mixes were prepared in which the sand was composed of a binary 
Table 1 Chemical composition and physical properties of cement and LP.

\begin{tabular}{c|c|c}
\hline Compounds (\%) & Cement & LP \\
\hline \hline $\mathrm{CaO}$ & 63.55 & 53.1 \\
\hline $\mathrm{SiO}_{2}$ & 23.24 & 0.54 \\
\hline $\mathrm{Al}_{2} \mathrm{O}_{3}$ & 4.72 & 0.29 \\
\hline $\mathrm{Fe}_{2} \mathrm{O}_{3}$ & 3.84 & 0.21 \\
\hline $\mathrm{MgO}$ & 0.65 & 0.84 \\
\hline $\mathrm{K}_{2} \mathrm{O}$ & 0.4 & 0.05 \\
\hline $\mathrm{SO}_{3}$ & 0.28 & 0.03 \\
\hline $\mathrm{Na}_{2} \mathrm{O}$ & 0.1 & $/$ \\
\hline $\mathrm{Cl}$ & $/$ & 0.1 \\
\hline Free CaO & 0.52 & $/$ \\
\hline Insoluble residue & 0.5 & 0.4 \\
\hline Loss of ignition & 2.15 & 44.4 \\
\hline Specific density & 3.1 & 2.7 \\
\hline Blaine Surface $\left(\mathrm{cm}^{2} / \mathrm{g}\right)$ & 3950 & 3200 \\
\hline
\end{tabular}

blend of DS and river sand (RS) with different proportions of DS $(0,10,20$ and $30 \%)$.

\section{Experimental program}

\subsection{Materials}

An ordinary Portland cement (CEM I 42.5) and a limestone type powder (LP) were used. The chemical and physical properties of cement and LP are given in Table 1. The sand used was a mixture of natural DS and RS. Selected sands are subjected to grain size distribution analysis as per XP P 18-540 standard. ${ }^{9}$ The set of sieves are taken from $5 \mathrm{~mm}$ to $0.08 \mathrm{~mm}$ with aggregate and sieve shaker subjected to vibration for 15 minutes. The particle size gradation obtained thorough sieve analysis method and physical properties of DS and RS are grouped in Table 2. The obtained results show that DS is characterized by its fineness and cleanness. Moreover, X-Rays Diffraction (XRD) analysis and Scanning Electron Microscope (SEM) view of DS grains are given in Figs. 1 and 2 respectively. The XRD analysis of DS demonstrates their essentially siliceous nature and SEM investigation reveals the rounded shape of their fine grains. A polycarboxylate-type third
Table 2 Sieve analysis and physical properties of used sands (DS and RS).

\begin{tabular}{c|c|c}
\hline \multirow{2}{*}{ Sieve size $(\mathrm{mm})$} & \multicolumn{2}{|c}{ Cumulative passing (\%) } \\
\cline { 2 - 3 } & $\mathrm{DS}$ & $\mathrm{RS}$ \\
\hline \hline 5 & 100 & 99.5 \\
\hline 4 & 100 & 97.09 \\
\hline 2.5 & 100 & 83.56 \\
\hline 1.25 & 99.92 & 63.27 \\
\hline 0.63 & 98.09 & 34.85 \\
\hline 0.315 & 82.86 & 13.65 \\
\hline 0.16 & 19.36 & 2.44 \\
\hline 0.08 & 1.63 & 0.84 \\
\hline Specific density & 2.7 & 2.56 \\
\hline Fineness modulus & 1 & 3.03 \\
\hline Sand equivalent & 91 & 87.7 \\
\hline Absorption (\%) & 2.18 & 0.59 \\
\hline Moisture content (\%) & 1 & 0.33 \\
\hline
\end{tabular}

generation high range water reducing superplasticizer (SP) conforming to the NF EN 934-2 standard ${ }^{10}$ was used. The solid content, $\mathrm{pH}$ and specific gravity are $30 \%, 6$ and 1.07 respectively.

\subsection{Mixtures proportions}

The mix proportion method is based on optimizing the maximum packing mass volume of dry mixture ${ }^{11}$ : The cement content is fixed, the LP content is selected, and the cement-LP mixture is completed by adding sand until obtaining a volume determined after dry mixing and $15 \mathrm{~s}$ of vibration on a vibrating table. Basing on the results of Bédérina et al., ${ }^{2}$ the LP/sand (LP/S) ratio was kept constant to 0.1 . Four mixes were prepared having constant cement content of $350 \mathrm{~kg} / \mathrm{m}^{3}$, constant LP content of $146 \mathrm{~kg} / \mathrm{m}^{3}$, constant water/binder ratio (W/B) of 0.44 and a constant SP dosage of 1.5 $\%$. A total sand content of $1456 \mathrm{~kg} / \mathrm{m}^{3}$ was used, in which RS was replaced by different proportions of DS $(0,10,20$ and $30 \%$ by weight of total sand). The different proportions of DS and RS are summarized in Table 3.

\subsection{Testing procedures}

As mentioned above, the sand used to prepare FSC mixes was

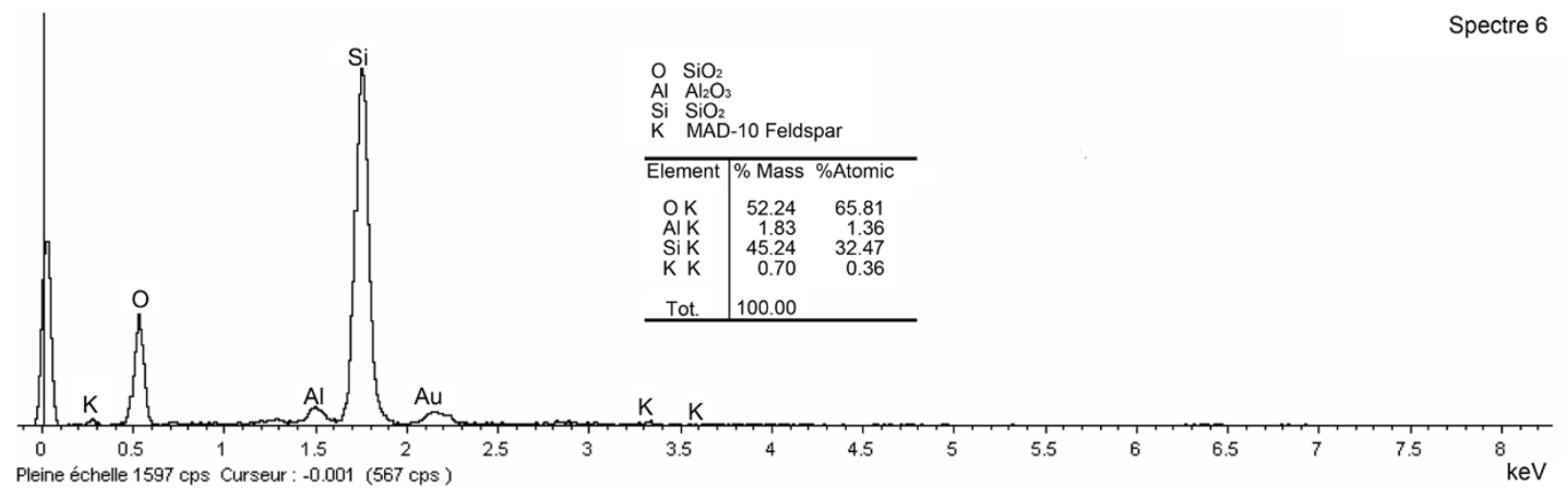

Fig. 1 X-Ray Diffraction pattern of DS. 


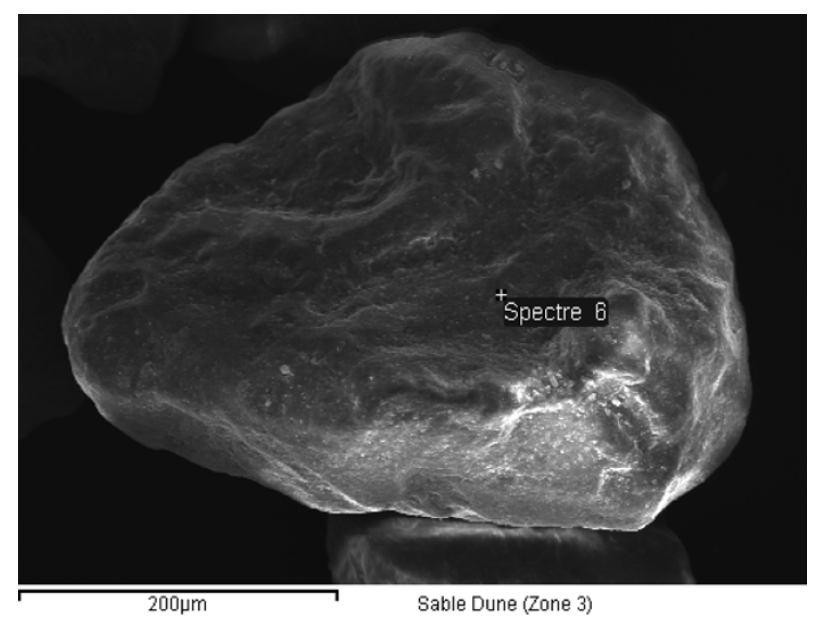

Fig. 2 View of fine DS grain (SEM analysis).

Table 3 Proportions of DS and RS in prepared mixes.

\begin{tabular}{c|c|c|c}
\hline \multirow{2}{*}{ Mix N } & \multicolumn{2}{|c|}{ DS } & RS \\
\cline { 2 - 4 } & $\%$ & $\left(\mathrm{~kg} / \mathrm{m}^{3}\right)$ & $\left(\mathrm{kg} / \mathrm{m}^{3}\right)$ \\
\hline \hline 1 & 0 & 0 & 1456 \\
\hline 2 & 10 & 146 & 1310 \\
\hline 3 & 20 & 291 & 1165 \\
\hline 4 & 30 & 437 & 1019 \\
\hline
\end{tabular}

composed from DS and RS with different concentrations of DS $(0,10,20$ and $30 \%)$. For that, the compactness of different sands used was measured at first, using their apparent and absolute densities as shown in the following relation.

$$
C=\rho_{\text {apparent }} / \rho_{\text {absolute }}
$$

Thereafter, all FSC mixes were prepared in identical mixing process to ensure similarity and uniformity. The mixing sequence consisted of homogenizing the binder and sands during one minute using standard mixer described by NF EN 196-1 standard. ${ }^{12}$ Then, half of the mixing water was added and mixed for another one minute. Next, the remaining water and SP were added and the mixing was continued for three minutes.

The fresh properties of FSC were investigated by using minislump, v-funnel and viscosity tests. Mini-cone slump and v-funnel tests (Figs. 3 and 4) were used in conformity with EFNARC. ${ }^{13}$

The viscosity was measured using a programmable DV-II+ rotational viscometer equipped with the RV4 mobile geometry (Fig. 5). In this type of viscometer, slip was most pronounced at low strain rates and led to unusual low viscosity readings. As the deformation rate increased, the influence of slip decreased. For this reason, the viscosity measurements were conducted at different rotational speeds. The FSC was prepared and placed on the pot of the viscometer. Pre-mixing was performed by increasing the rotational speed from 0 to $60 \mathrm{rpm}$ in $120 \mathrm{~s}$. As soon as the highest rotational speed was reached, the viscometer stopped. After this initial preparation, a full cycle of increasing rotational speed in eight steps from $0.3 \mathrm{rpm}$ to $60 \mathrm{rpm}$ and back to reset with the same steps was performed. For each rotational speed step, the average of viscosity reading is recorded. This procedure was performed at the beginning (at $\mathrm{t}=0 \mathrm{~min}$ ) and after 20 minutes. ${ }^{14}$

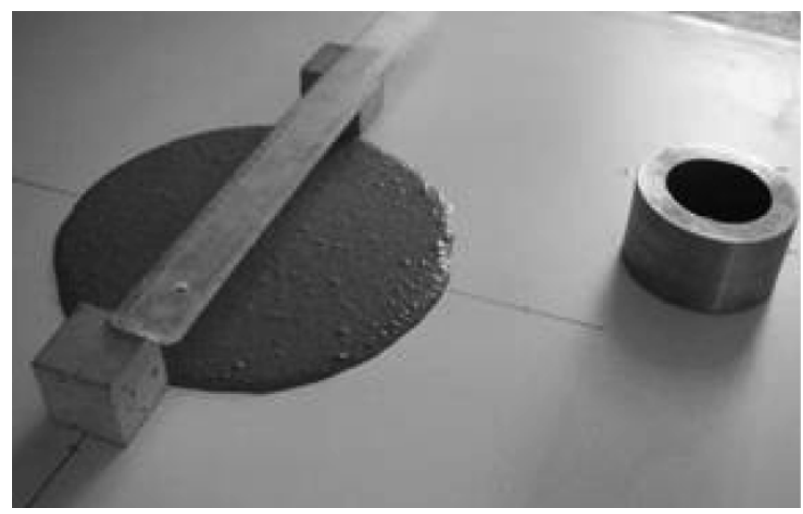

Fig. 3 Mini-slump test for fresh FSC.

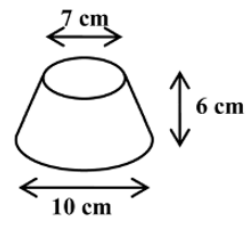

(a)

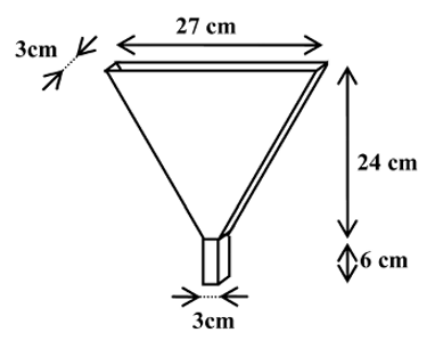

(b)
Fig. 4 Dimensions in $(\mathrm{cm})$ of mini-slump cone and v-funnel.

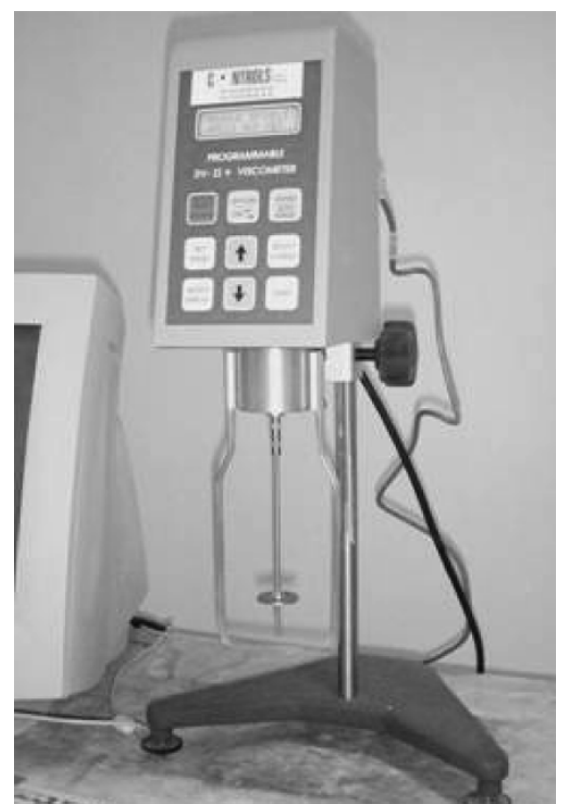

Fig. 5 Programmable DV-II+ viscometer.

Tests for compressive strength of hardened FSC were also conducted. Specimens were cast in stainless steels molds with dimensions of $40 \times 40 \times 160 \mathrm{~mm}$. The specimens were demoulded one day after casting and were conserved in a water bath under constant temperature. After 28 days of curing the compression tests were carried out.

\section{Results and discussions}

The influence of DS on compactness of total sand mixture is 


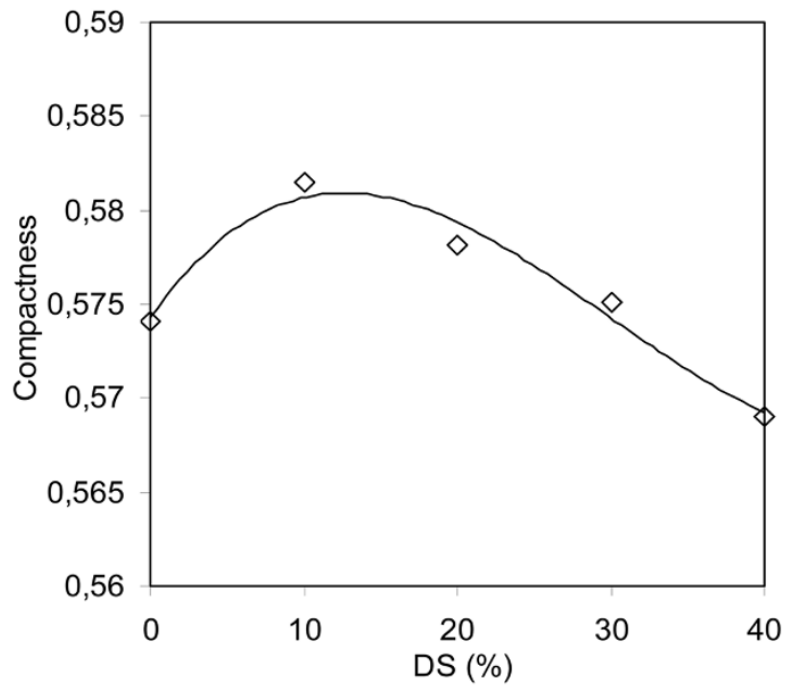

Fig. 6 Evolution of sand compactness in function of DS concentrations.

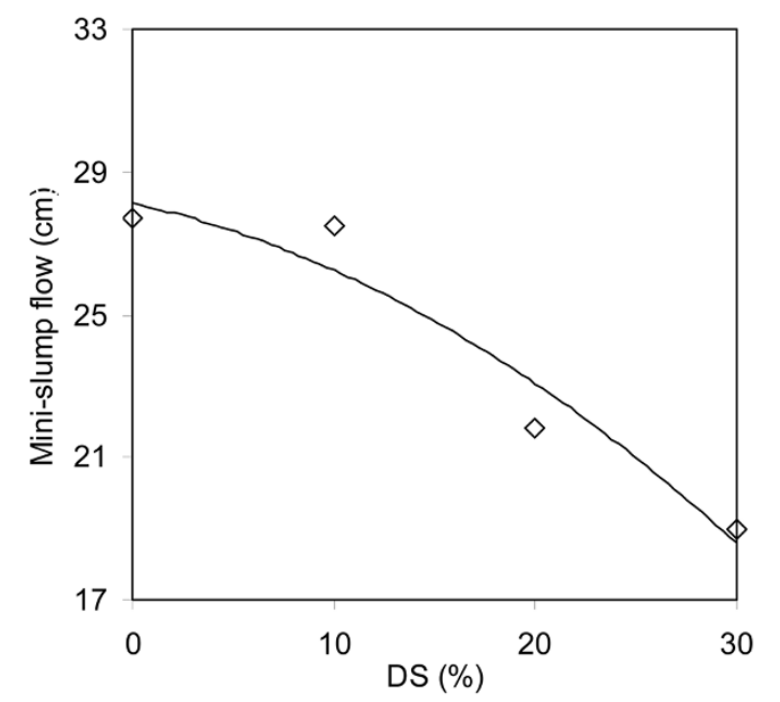

Fig. 7 Effect of DS concentrations on the mini-slump diameter of FSC.

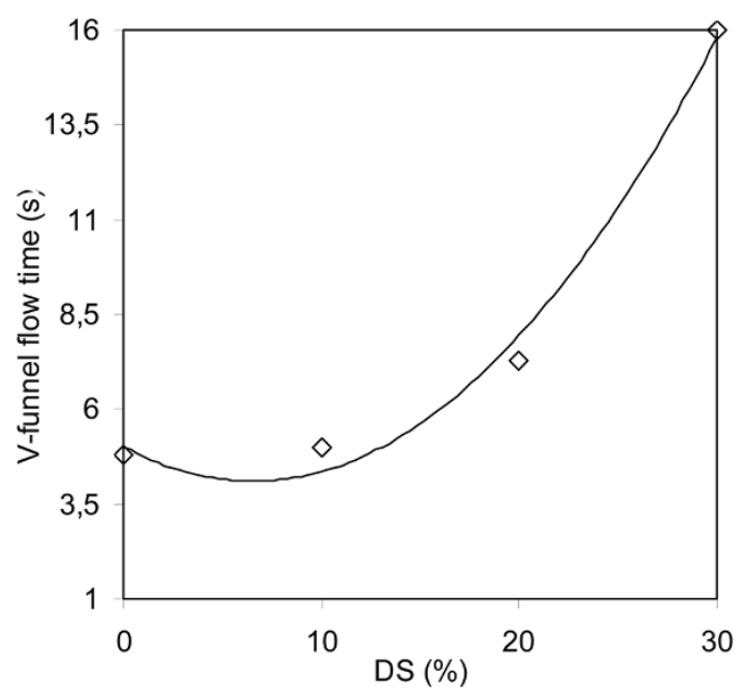

Fig. 8 Effect of DS concentrations on the v-funnel flow time of FSC. shown in Fig. 6. From these results, it can be observed that by increasing the DS concentration, the compactness increased until a maximum value (around 10\%) and then decreased. This can be explained by the filling effect, i.e. before reaching maximum compactness, the fine grains of DS filled spaces between the coarser grains of RS, thereby increasing the compactness of the mixture. Once the voids were completely filled, the fine grains then began to occupy the place of coarser grains, and consequently the compactness of the mixture decreases.

The test results on the effects of DS concentrations on changes in mini-cone slump diameter and $\mathrm{v}$-funnel flow time are illustrated in Figs. 7 and 8 respectively. Results presented in Fig. 7, show that increasing of DS concentration reduced the mini-cone slump diameter. In Fig. 8, results show that the increasing in DS concentration reduced the v-funnel flow time, until a minimum value (between 0 and 10\%) before increasing to higher values for 20 and $30 \%$ in DS. The decrease in mini-cone diameter and v-funnel flow time is due to the large finesses of DS and to their need for water $^{15}$ (Absorption coefficient of DS $=2.18 \%$ ). The minimum value of $\mathrm{v}$-funnel flow time obtained at $10 \%$ of DS is may be due to the higher compactness of aggregate, which results in a smaller volume of void to be filled and hence larger amount of excess paste is gained for lubrication purpose.

The results of viscosity measurements show that the behaviour of all mixes was similar (pseudo-plastic) and can be best fitted with the power-law model (Eq. 2):

$$
\mu=a \cdot \gamma^{b}
$$

Where $\mu$ is the viscosity, $\gamma$ is the rotational speed of mobile part, $\mathrm{a}$ and $\mathrm{b}$ are constants (called also consistency index and flow index respectively). The coefficients of correlation and constants calculated by using this model are recapitulated in Table 4. Variations in the viscosity of FSC according to the rotational speed and the content of DS are given in Figs. 9 and 10. In general, it was observed that at low rotational speed a viscous behaviour is marked, whereas at high rotational speed a flowable behaviour is governing. It was also observed a viscous behaviour of all FSC mixes with time (at $\mathrm{t}=20 \mathrm{~min}$ ). This result is in agreement with the findings of the other studies reported in the literature. ${ }^{14,16-19}$ Figs. 9 and 10 show that there is an optimal DS concentration (at $10 \%$ ), for which FSC mixes present the lowest viscosities. This is may be a result of the high compactness of aggregates at this concentration of DS, which results in an excess paste for lubrication purpose. ${ }^{19}$ The effect of DS was similar after $20 \mathrm{~min}$, with a more

Table 4 Constants ( $a$ and $b$ ) and correlation coefficients of the model curves.

\begin{tabular}{|c|c|c|c|c|c|}
\hline \multirow{2}{*}{\multicolumn{2}{|c|}{$\frac{\text { Mix } \mathrm{N}^{\circ}}{\text { Model constants }}$}} & \multirow{2}{*}{1} & \multirow{2}{*}{2} & \multirow{2}{*}{3} & \multirow{2}{*}{4} \\
\hline & & & & & \\
\hline \multirow{3}{*}{ At $0 \mathrm{~min}$} & $\mathrm{a}$ & 23268 & 20569 & 37296 & 34940 \\
\hline & b & -0.6261 & -0.5923 & -0.6170 & -0.6474 \\
\hline & $\mathrm{R}^{2}$ & 0.98 & 0.98 & 0.99 & 0.99 \\
\hline \multirow{3}{*}{ At $20 \mathrm{~min}$} & $\mathrm{a}$ & 27309 & 24785 & 53499 & 49427 \\
\hline & b & -0.6076 & -0.5807 & -0.7091 & -0.8371 \\
\hline & $\mathrm{R}^{2}$ & 0.98 & 0.98 & 0.99 & 0.99 \\
\hline
\end{tabular}


(a) $\mathrm{T}=0 \mathrm{~min}$

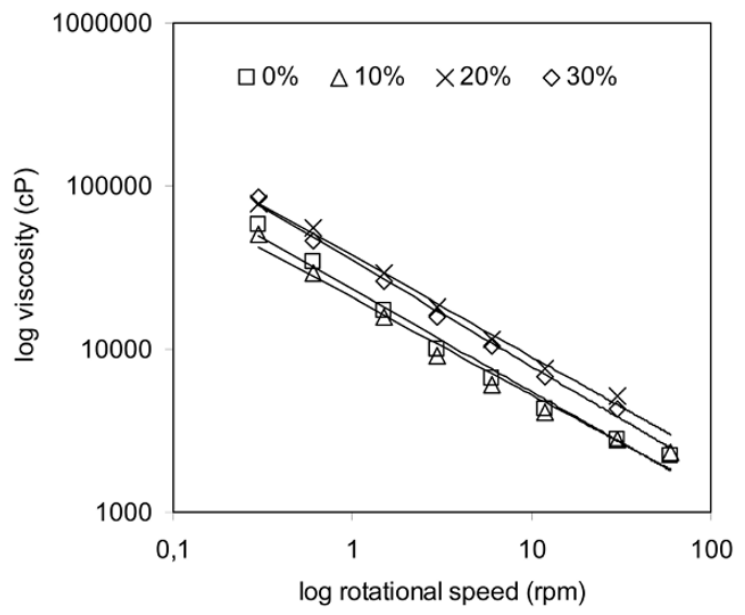

Fig. 9 Effect of DS concentrations on viscosity (at $0 \mathrm{~min}$ ) of FSC.

(b) $\mathrm{T}=20 \mathrm{~min}$

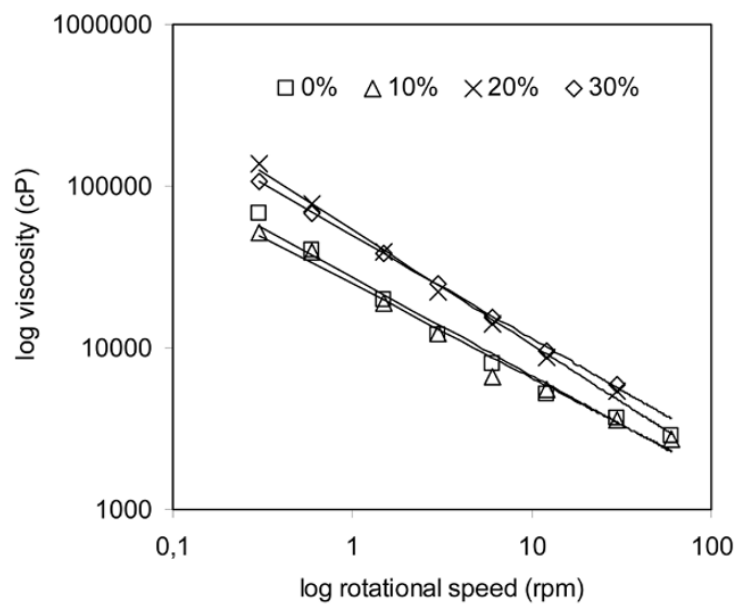

Fig. 10 Effect of DS concentrations on viscosity (at $20 \mathrm{~min}$ ) of FSC.

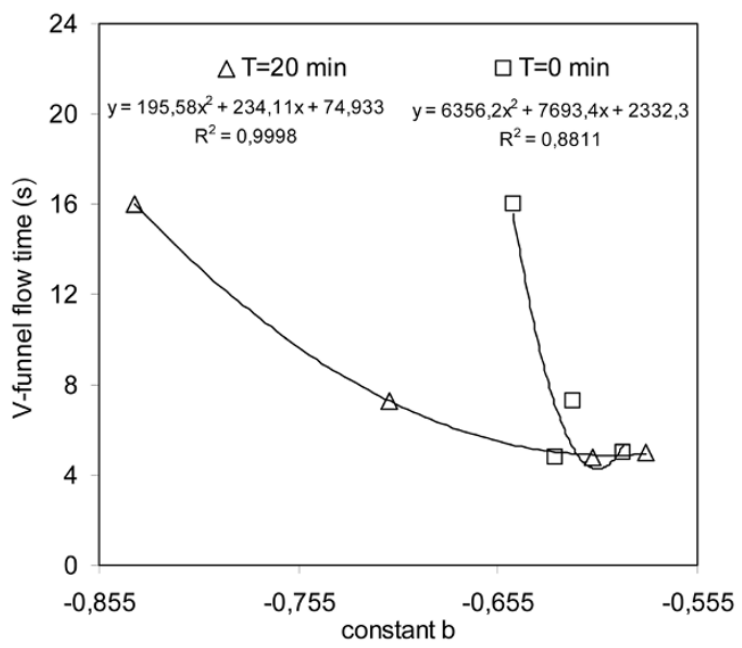

Fig. 11 Correlation between v-funnel flow time and constant $b$.

viscous behaviour of FSC mixes.

Several authors have studied the relationship between $v$-funnel

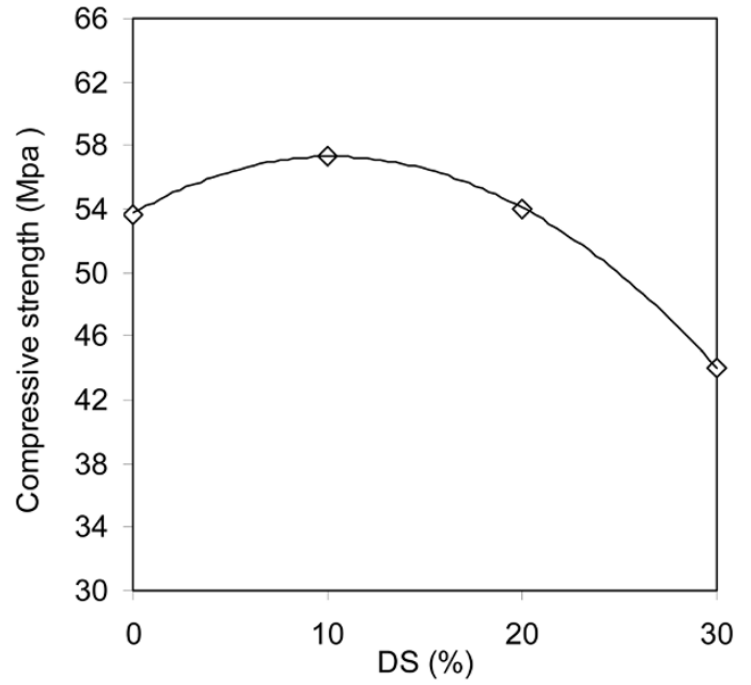

Fig. 12 Effect of DS on 28-day compressive strength of FSC.

flow time and viscosity at different rotational speeds. They have concluded that v-funnel flow time correlates in certain cases with the viscosity measurements. In a study on the viscosity of selfcompacting repair mortars, Felekoğlu et al. ${ }^{14}$ have found that the best correlation between $\mathrm{v}$-funnel flow time and viscosity was derived from the rotational speed $10 \mathrm{rpm}$. Recently, Güneyisi et al. ${ }^{17}$ have found this correlation at $0.5 \mathrm{rpm}$. As a less sophisticated test, $\mathrm{v}$-funnel flow time correlate in certain cases with some rotational speed of viscometer. However, the coefficients of correlation of the relations seem not very strong and may only reflect the general tendency. $^{14}$

The full-log scale representation of viscosity curves depending on rotational speed allows obtaining straight lines (Figs. 9 and 10), where the constant $b$ of each curve represents the slope of the corresponding line. The Fig. 11 shows that the constant $b$ and v-funnel flow time are best-correlated with good values of coefficients correlation $\left(\mathrm{R}^{2}=0.88\right.$ at $\mathrm{t}=0$ min and $\mathrm{R}^{2}=0.99$ at $\left.\mathrm{t}=20 \mathrm{~min}\right)$. The correlation results show that when constant $b$ increases, v-funnel flow time decreases. In other words, when constant $b$ is important for a given mix, lower energy will be necessary to attain flowable consistency.

The compressive strength results of hardened FSC are given in Fig. 12. From these results, it can be seen that the concentration of the DS has an optimal value (about 10\%), for which the compressive strength at 28 days is better. This is may be a result of the high compactness of aggregates at $10 \%$ of DS.

\section{Conclusions}

From the findings of this experimental investigation for flowing sand concrete (FSC), the following conclusions can be extracted:

1. Although the sand concrete has been commonly used as a building material since ancient times, recovery of dune sand (DS) remains one of the major problems for the environmental concerns in Saharan regions. However, this study emphasises that this material can be utilized in FSC containing as principal aggregate natural sands.

2. By using DS (around $10 \%$ by mass of total sand) with river sand (RS) the compactness of sand grains can be improved. 
Thereby, the amount of excess paste can be considerably increased and consequently the fluidity of FSC will be improved. The obtained optimum concentration of DS has allowed achieving FSC mixes with lowest v-funnel flow time and minimum viscosity values.

3. Using the flow index (constant $b$ ) of best-fitted model curves of viscosity changes depending on rotational speed, the flowability of the mixes can be characterized. In other words, higher is constant $b$, higher will be the flowability. A polynomial relationship between constant $b$ and v-funnel measurements, with acceptable coefficients of correlations, were obtained $\left(\mathrm{R}^{2}=0.88\right.$ at $\mathrm{t}=0 \mathrm{~min}$ and $\mathrm{R}^{2}=0.99$ at $\mathrm{t}=20 \mathrm{~min}$ ).

4. The optimum concentration of DS (10\%), which allows the FSC to have a good fluidity, also allows for better performance in terms of compressive strength at 28 days.

\section{References}

1. Sablocrete, Synthèse du Projet National de Recherche et Développement, Bétons de sable, caractéristiques et pratiques d'utilisation, Presses de l'école Nationale des Ponts et Chaussées LCPC, Paris, 1994 (In french).

2. Bédérina, M., Khenfer, M. M., Dheilly, R. M., and Quéneudec, M., "Reuse of local sand: effect of limestone filler proportion on the rheological and mechanical properties of different sand concretes", Cement and Concrete Research, Vol. 35, No. 6, 2005, pp. 1172 1179.

3. Akrout, K., Mounanga, P., Ltifi, M., and Ben Jamaa, N., "Rheological, Mechanical and Structural Performances of Crushed Limestone Sand Concrete", International Journal of Concrete Structures and Materials, Vol.4, No.2, 2010, pp. 97 104.

4. Rmili, A., Ben Ouezdou, M., Added, M., and Ghorbel, E., "Incorporation of Crushed Sands and Tunisian Desert Sands in the Composition of Self Compacting Concretes Part I: Study of Formulation", International Journal of Concrete Structures and Materials, Vol.3, No.1, 2009, pp. 3 9.

5. Brouwers, H. J. H. and Radix, H. J., "Self-compacting concrete: the role of the particle size distribution". First International Symposium on Design, Performance and Use of SCC, Hunan, China, 2005, pp. 109 118.

6. Kosmatka, S. H. and Panarese, W. C., Design and control of concrete mixtures, $13^{\text {th }}$ Ed., Portland Cement Association Skokie, IL, 1988.

7. Mehta, P. K. and Monteiro, P. J. M., Concrete: Structure, properties and materials, Prentice-Hall Prentice Hall College Div., 2 Sub-edition, 1992.
8. Chang, P. K., Hwang, C. L., and Peng Y. N., "Application of high performance concrete to high rise building in Taiwan", Advances in Structural Engineering, Vol. 4, No. 2, 2001, pp. $65 \sim 73$.

9. XP P 18-540 Standard, Granulats: Définitions, conformité, spécifications, Association Française de Normalisation (AFNOR), Paris, 1997 (In french).

10. NF EN 934-2 Standard, Béton et constituants des bétons, Tome 1: spécification du béton et de ses constituants, $5^{\mathrm{ème}}$ Ed., Association Française de Normalisation (AFNOR), Paris, 2002 (In french).

11. Chauvin, J. J. and Grimaldi, G., "Les bétons de sable", Bulletin de liaison Laboratoires des Ponts et Chaussées (LCPC), No. 157, 1988, pp. 9 15 (In French).

12. NF EN 196-1 Standard, Ciments et chaux, Association Française de Normalisation (AFNOR), Paris, 2003 (In french).

13. EFNARC, The European guidelines for self-compacting concrete, Specification, Production and use, The European Federation of Specialist Construction Chemicals and Concrete Systems, 2002.

14. Felekoğlu, B., Tosun, K., Baradan, B., Altun, A., and Uyulgan, B., "The effect of fly ash and limestone fillers on the viscosity and compressive strength of self-compacting repair mortars", Cement and Concrete Research, Vol. 36, No. 9, 2006, pp. 1719 1726.

15. Rmili, A., Ben Ouezdou, M., Added, M., and Ghorbel, E., "Incorporation of Crushed Sands and Tunisian Desert Sands in the Composition of Self Compacting Concretes Part II: SCC Fresh and Hardened States Characteristics", International Journal of Concrete Structures and Materials, Vol. 3, No. 1, 2009, pp. $11 \sim 14$.

16. Güneyisi, E. and Gesoğlu, M., "Properties of selfcompacting mortars with binary and ternary cementitious blends of fly ash and metakaolin", Materials and Structures, Vol. 41, No. 9, 2008, pp. 1519 1531.

17. Güneyisi, E., Gesoğlu, M., and Özbay E., "Effect of marble powder and slag on the properties of self compacting mortars", Materials and Structures, Vol. 42, No. 6, 2009, pp. 813 826.

18. Bouziani, T., Benmounah, A., Bédérina, M., and Lamara, M., "Effect of Marble Powder on the Properties of Self-Compacting Sand Concrete", The Open Construction and Building Technology Journal, Vol. 5, 2011, pp.25 29

19. Wong, H. H. C. and Kwan, A. K. H., "Packing density of cementitious materials: part1-measurement using a wet packing method", Materials and Structures, Vol. 41, No. 4, 2008, pp. 689 701. 